\title{
I Paint the Town Red: An Overview of English Idioms Through the Lens of Computational Corpus
}

\author{
$1^{\text {st }}$ L. Septianasari \\ STKIP Muhammadiyah Bogor \\ Bogor, Indonesia
}

\author{
$2^{\text {nd }}$ Triyanto \\ STKIP Muhammadiyah Bogor \\ Bogor, Indonesia
}

\begin{abstract}
Idiomatic expressions are commonly used by the native speakers to express their idea. Aside from that, this linguistic term also brings the philosophical value of the speakers. The aims of this research are to investigate the philosophical value of the word red in English idioms and to examine the use of these idioms by using the corpus. A record maintenance data collecting technique is used to collect the data. The data were taken from American English Idioms Dictionary and English Corpus. The referential approach is used to analyze the data. The results show that the red color in English idioms has positive and negative contextual meaning. Moreover, during the use of these idioms from time to time, transformation and variation are found in the use of these terms in daily conversation.
\end{abstract}

\section{Keywords-Idioms, Corpus, Philosophical value, Transformation}

\section{INTRODUCTION}

The rapid growth of technology eases scientists from any field of study to conduct research, including research in language study. In synchronic and diachronic research of language, computational corpus really helps linguists to analyze the development of language. In the last three decades, the massive use of corpora has boosted many types of research on linguistic issues. Thousands of data of the utterances from language users are documented and can be easily accessed by any linguists who need it as the source of their data. Therefore, it is quite relevant when Hunston notified that the corpus brought a revolution in linguistic research [1]. Moreover, Meyer remarks a point that many linguists are interested in conducting descriptive or even theoretical language study by using linguistic corpora to collecting the data [2]. Corpus provides an authentic bank of data that serves language use from time to time. Linguists and language teachers are able to investigate the current usage and characteristics of language through Corpus tools [3].

By using a corpus, we can investigate the development and change of language use from time to time. The change of language occurs almost in all linguistic units, including the change in idiomatic expressions or figurative language. Idioms as formulaic sequence have a fixed and or semifixed form which can be transformed and modified by the language users as long as this modification still delivers the same meaning. Almohizea presented arguments to emphasize that in the traditional approach, idioms are viewed as a separate substance in the lexicon. Meanwhile, in the non-traditional approach, idioms are associated with human cognition. Thus, the use of this formulaic sequence is emphasized in the meaning rather than to its grammatical complexity [4].

Each idiom brings their idiomatic meaning which some are quite philosophical since it reflects an ideology and culture of the interlocutors. Thus, a single constituent word of idioms may symbolize the thought of the interlocutors. Besides, the rapid diachronic use of idioms shows their character that some of them are not fully opaque and fixed [5] [6][7]. Previous studies proved that these fixed expressions can also be quite flexible in its use [8][9]. Generally speaking, the objective of this research is to shed light on the philosophical meaning of the word "red" in English idioms and the use of these idioms in the current English language community documented in English Corpus.

\section{LITERATURE REVIEW}

A. Idioms in Traditional and Non-Traditional Approach An idiom is a type of multi-word unit that can easily be found in the daily conversation since these phraseological expressions can be used in informal and formal occasions. Idioms have their own distinctive meaning which cannot be interpreted lexically [10] [11]. Thus, it can be challenging to research this type of phraseological unit. In a traditional approach, the research in the idiom is focused on its motivation and structure. Almohizea grouped structural and generative approaches as the part of traditional approach since these approaches focused on two problematic domains, such as the representative of idioms in language users' mental lexicon and the syntactical behavior of those idioms [4]. This view is a manifestation of the theoretical view in structuralism [12].

Hockett in his book claimed that the smallest constituent of an idiom is a free morpheme, which, however, this theory lacks further evidence to differ idiom from other formulaic sequences [13]. This definition does not carry out a specific character of the idiom by the fact that some lexical elements are involved [4]. Another insight into the traditional approach comes from Katz and Postal that viewed idiom as a unique linguistic unit with uncommon productivity [14]. Generally speaking, idioms 
are investigated from its grammatical behavior in this approach.

A number of significant studies of idioms have been published by linguists through the non-traditional approach. This approach tends to investigate Lifestyle based on the cognitive linguistic approach instead of observing this formulaic sequence only through the generative and structural approaches. In the non-traditional approach, idioms are treated not only through a syntactical and generative approach, but also through the cognitive approach [5][15][16]. Idioms are studied by monitoring their usage in the speaker's utterance. They are treated fully by investigating their behavior in syntactical, semantic, and cognitive units. Out of its basic character as the part of a fixed expression, the syntactical features of an idiom may transform or change arbitrarily [10][17].

\section{B. The Phraseology of Idioms}

The phraseological term of idioms is changeable even though this formulaic sequence is categorized as a fixed expression. Some researches of idioms with non-traditional approaches noticed that transformation and variation happened to change their phraseological constituents without changing the meaning [5][18]. 9 types of prototypical idiom phraseology are commonly found in English learners' dictionary, such as the phrasal verb, irreversible binomials, tournures, catchphrase, proverb, pragmatic idioms, animal metaphors, idiomatic similes, allusion and allusive idioms [19]. However, saying is not categorized as idiom since it is different from idiom. Saying is always performed in a full sentence to carry a moral message, therefore, it is syntactically and semantically different from idiom [20].

A phraseological expression or idiomatic expression or phraseme is tied in a special rule [21]. Even though idioms are a part of fixed expressions, syntactically their constituent words can be changed into other lexemes as long as the change semantically can still deliver the same message. Looking at the use of idiom we find in corpora, grammatical transformations are produced by the interlocutors to communicate. It shows that the phrase of this multi-word unit is not fully fixed diachronically. However, it is only a pure idiom that is opaque and fixed [22].

As time goes by, many kinds of transformations and variations of idioms are studied by linguists [5][8][7]. Moon classified transformations of idioms into 8 clusters
[5]. The first type is the polarity. It is characterized by the change of grammatical pattern of the idiom from positive to negative or vice versa. The second type is passivization which happens when active construction is used by the interlocutors into passive construction. The third category is nonfinite uses. The next categories are embedding, pronominalization, nominalization, transformation to adjective, and transformation to predicate. On the other hand, variation is classified into lexical variations and systematic variations.

\section{RESEARCH METHOD}

This qualitative research used unstructured data which is taken from corpus and dictionary. Lexeme red is used to limit the source of data and to round up the idioms from the American English dictionary. The first thing that we did in collecting the data is by collecting all idioms with red from Dictionary of American Idioms and Phrasal Verbs (DAIPV) written by Richard A. Spears [23]. This idioms dictionary was published in 2005, therefore, to zoom in the current usage of the idioms in research data, the next thing that we did was to record the usage by crosschecking the unstructured data from COCA (Corpus of Contemporary American English). The collected data were analyzed by using some theories about the meaning and flexibility of idioms from Spears [23] and Moon [5] to zoom in the investigation.

\section{A. Meaning association}

\section{DISCUSSION}

As the problem of the research is limited to idioms with red as its constituent unit, we collected 14 idioms from DAIPV [23]. However, these idioms are synchronically fixed as they become the lemma of this idioms dictionary. Nonetheless, we investigated how far the flexibility of these fixed expressions diachronically. Besides, we also analyzed their meanings based on their definitions in the dictionary and their contextual use in interlocutors' speaking production. In Table 1, we displayed the collected data and their contextual semantic polarity. We divided them into 2 terms, positive and negative. This classification is taken by considering the situational context of the use of each idiom. Some of them are used in a positive situation, but the other idioms are used in a negative situation. Here are the complete data.

TABLE I. IDIOMS WITH RED AS THE CONSTITUENT UNIT

\begin{tabular}{|c|c|c|c|c|c|}
\hline \multirow[t]{2}{*}{ No. } & \multirow{2}{*}{ Idioms taken from DAIPV } & \multirow{2}{*}{ Dictionary's meaning } & \multicolumn{2}{|c|}{ Contextual Semantic Polarity } & \multirow{2}{*}{ Association } \\
\hline & & & Positive & Negative & \\
\hline 1. & catch someone red-handed & $\begin{array}{l}\text { to catch a person in the act of doing } \\
\text { something wrong }\end{array}$ & - & $\sqrt{ }$ & Crime \\
\hline 2. & cut through red tape & $\begin{array}{l}\text { to eliminate or neutralize something } \\
\text { complicated, such as bureaucratic } \\
\text { rules and procedures. }\end{array}$ & $\sqrt{ }$ & - & Bureaucracy \\
\hline 3. & down the little red lane & $\begin{array}{l}\text { down someone's throat; down a } \\
\text { child's throat. }\end{array}$ & $\sqrt{ }$ & - & Physical activity \\
\hline 4. & give someone a red face & $\begin{array}{l}\text { to make someone visibly } \\
\text { embarrassed. }\end{array}$ & - & $\sqrt{ }$ & $\begin{array}{c}\text { Cruelty/ negative } \\
\text { behavior }\end{array}$ \\
\hline 5. & in the red & $\begin{array}{l}\text { losing money. (*Typically: be } \sim \text {; go } \\
\text { [into] ; as opposed to in the black.) }\end{array}$ & - & $\sqrt{ }$ & Finance \\
\hline 6. & one's ears are red & $\begin{array}{l}\text { [for someone's ears] to be red from } \\
\text { embarrassment. }\end{array}$ & - & $\sqrt{ }$ & $\begin{array}{c}\text { Negative } \\
\text { emotion }\end{array}$ \\
\hline
\end{tabular}




\begin{tabular}{|c|c|c|c|c|c|}
\hline \multirow[t]{2}{*}{ No. } & \multirow[t]{2}{*}{ Idioms taken from DAIPV } & \multirow[t]{2}{*}{ Dictionary's meaning } & \multicolumn{2}{|c|}{ Contextual Semantic Polarity } & \multirow[t]{2}{*}{ Association } \\
\hline & & & Positive & Negative & \\
\hline 7. & out of the red & out of debt; into profitability & $\sqrt{ }$ & - & Finance \\
\hline 8. & paint the town (red) & to go out and celebrate & $\sqrt{ }$ & - & Positive emotion \\
\hline 9. & a red herring & $\begin{array}{l}\text { a piece of information or suggestion } \\
\text { introduced to draw attention away } \\
\text { from the real facts of a situation. }\end{array}$ & - & $\sqrt{ }$ & Crime \\
\hline 10. & red ink & $\begin{array}{l}\text { debt; indebtedness as shown in red } \\
\text { ink on a financial statement. }\end{array}$ & - & $\sqrt{ }$ & Finance \\
\hline 11. & red tape & $\begin{array}{l}\text { over-strict attention to the wording } \\
\text { and details of rules and regulations, } \\
\text { especially by government workers. } \\
\text { (From the color of the tape used by } \\
\text { government departments in England } \\
\text { to tie up bundles of documents.) }\end{array}$ & - & $\sqrt{ }$ & Bureaucracy \\
\hline 12. & the red-carpet treatment & $\begin{array}{l}\text { very special treatment; royal } \\
\text { treatment. }\end{array}$ & $\sqrt{ }$ & - & Positive behavior \\
\hline 13. & red-letter day & $\begin{array}{l}\text { an important or significant day. } \\
\text { (From the practice of printing } \\
\text { holidays in red on the calendar.) }\end{array}$ & $\sqrt{ }$ & - & Special date \\
\hline 14. & see red & to be angry. & - & $\sqrt{ }$ & $\begin{array}{l}\text { Negative } \\
\text { emotion }\end{array}$ \\
\hline
\end{tabular}

(source: Dictionary of American Idioms and Phrasal Verbs/DAIPV [23])

According to the table above, 8 out of 14 idioms are commonly used in a negative or bad situation and the other 6 idioms can be used in a positive situation. It means that some idioms are used for negative contextual meaning and vice versa.

Based on their meanings, those idioms are associated with negative and positive acts. Data number (1), (4), (6), (9), and (14) can be used to express negative acts. Meanwhile, others can be used to show positive acts, such as data number (8) and (12). Emotionally, the word red as an idiomatic constituent of multi-word expression is used to express anger (datum 14) and shyness (datum 6). Out of this case, this lexeme brings the other meaning associations in idioms, such as crime (data 1 and 9), bureaucracy (data 2 and 11), physical activity (datum 3), negative behavior or cruelty (datum 4), positive behavior (datum 12), finance (data 5, 7, and 10), negative emotion (data 6 and 14), positive emotion (datum 8), special date (datum 13).

B. Idioms, Its Use, and Flexibility

We observed the behavior of those idioms diachronically by using COCA. Most of those idioms are pure and fixed. Nonetheless, the others show their flexibility in their usage. We found variation and transformation of their usage as follows:

TABLE II. IDIOMS WITH RED AND THEIR TRANSFORMATION IN COCA

\begin{tabular}{|l|l|l|}
\hline Type of Transformation & Fixed Form in DAIPV & Its usage in COCA \\
\hline Passivization & $\begin{array}{l}\text { catch someone red-handed } \\
\text { (2005) }\end{array}$ & $\begin{array}{l}\text { (15) General, you were just caught red-handed having } \\
\text { an affair. (2012) }\end{array}$ \\
\hline Nominalization & cut through red tape (2005) & $\begin{array}{l}\text { (16) They're too technical for most people to understand } \\
\text { and " cutting red tape " doesn't make headlines (2012) }\end{array}$ \\
\hline
\end{tabular}

Idiom in datum (15) is the passivization of an idiom in datum (1). The language user used the passive form of the idiom to emphasizing the expression. On the other hand, the idiom in datum (2) is nominalized in datum (16). The

TABLE III. IDIOMS WITH RED AND THEIR VARIATION IN COCA

\begin{tabular}{|l|l|l|}
\hline Type of Variation & Fixed Form in DAIPV & Its usage in COCA \\
\hline Truncation & catch someone red-handed (2005) & $\begin{array}{l}\text { (17) This is also red-handed proof of their scheme to only } \\
\text { select comparisons..... (2012 }\end{array}$ \\
\hline Verb Variation & catch someone red-handed (2005) & (18) She had your bad boy red-handed. (2008) \\
\hline $\begin{array}{l}\text { Particle Variation and } \\
\text { Amplification }\end{array}$ & cut through red tape (2005) & $\begin{array}{l}\text { (19) It is best if the freakin' federal government cuts back } \\
\text { on the red tape and regulations. (2012) }\end{array}$ \\
\hline
\end{tabular}

(Source: DAIPV [23] and COCA)

The variations of idioms are categorized into 3 parts. The first part is truncation in which the shortening form as the constituent of the noun phrase 'red-handed proof' in datum (17). Verb variation is also found in datum (1) as the verb 'catch' is changed into 'had' in datum (18). In addition, particle variation is identified in datum (19) by the change of preposition 'through' into 'on'. Furthermore, amplification is notified by the addition of the word 'back' after the verb 'cut' in datum (19). occurred from the verb phrase in datum (1) into adjective change happened from verb phrase into a noun phrase. This idiom then becomes the subject of the sentence in datum (16).
Supporting what has been explained by Moon[5], it can be recognized from Tables 2 and 3 that several idioms with red as one of the idiom's constituent units are quite flexible. This flexibility shows that the human brain or cognition is creative. The interlocutors presented their creativity and productivity in using these formulaic sequences.

\section{CONCLUSION}

Based on its dictionary meaning, data of idioms in this research show that emotionally the word red can be used to express anger or shyness. We know that when we get angry 
or shy, our eyes, as well as our check or face, will be reddish. In addition, when the word red is used as a constituent unit, this lexeme help to construct the meaning associated to the expression used when we as the interlocutors talk about finance. It is because red ink was used to show indebtedness as shown on the financial statement. Moreover, this lexeme also can be associated with criminal stuff when it is used as an idiom's constituent unit gathered with other lexemes. It is known that red blood sometimes is found as the crime evidence, therefore, this word can be used to construct an idiom about crime. It can be concluded that the use of red in idioms' constructions are related to situational condition happen to human life. Lifestyle, culture, or philosophical thought becomes the foundation in several idioms construction.

Talking about the current use of idioms with red as one of the constituent units, after years the transformation and variation of these idioms are found in COCA even though some show their fixed behavior. A human with their brilliant cognition can be playful in using this fixed expression to communicate their thoughts. However, diachronically several idioms can behave flexibly in changing their fixed synchronic construction.

\section{REFERENCES}

[1] S. Hunston, Corpora in Applied Linguistics. Cambridge: Cambridge University Press, 2002.

[2] C. F. Meyer, English Corpus Linguistics: An Introduction. Cambridge: Cambridge University Press, 2002.

[3] N. D. Almutairi, "The Effectiveness of Corpus- Based Approach to Language Description in Creating Corpus-Based Exercises to Teach Writing Personal Statements," English Lang. Teach., vol. 9, no. 7, pp. 103-111, 2016.

[4] M. I. Almohizea, "The Placement of Idioms in Traditional and Non-Traditional Approaches," Int. J. Lang. Linguist., vol. 3, no. 5, pp. 40-49, 2016.

[5] R. Moon, Fixed Expressions and Idioms in English: A Corpus Based Approach. Oxford: Clarendon Press, 1998.

[6] O. Prysiazhna, L. Tulchak, N. Hadaichuk, and S. Medvedieva, "English Idioms: Transformation of Image," World Sci., vol. 9, no. 37 , pp. 66-68, 2018

[7] J. Parizoska and I. Rajh, "Idiom Variation in Business English Textbooks: A corpus-based Study," ESP Today J. English Spesific Purp. Tert. Lev., vol. 5, no. 1, pp. 46-67, 2017.

[8] A. Hovhannisyan and A. Mkrtchyan, "Transformation of Idioms and Transparency," J. Mod. Educ. Rev., vol. 4, no. 1, pp. 29-34, 2014.

[9] J. Liutkute, "The Problem of Idiomaticity and Phraseological Units' Transformation," Vilnius Pedagogical University, 2007.

[10] L. Septianasari, "Idiom dalam Novel The Kiss," Gadjah Mada University, 2015.

[11] T. Herbst, English Linguistics. New York: De Gruyter Mouton, 2010.

[12] D. Graddol, "Three Models of Language Description," in Media Texts: Authors and Readers, D. Graddol and O. Boyd-Barrett, Eds. Buckingham: Open University Press, 1993, pp. 1-21.

[13] C. F. Hockett, A Course in Modern Linguistics, The Macmil. U.S.A., 1958 .

[14] J. J. Katz and P. M. Postal, "The Semantic Interpretation of Idioms and Sentences Containing Them," MIT Res. Lab. Electron. O. Prog. Rep., vol. 70, pp. 275-282, 1963.

[15] A. P. Cowie, Phraseology: Theory, Analysis and Applications. Oxford: Clarendon Press, 2001.

[16] W. Croft and D. A. Cruse, Cognitive Linguistics. Cambridge: Cambridge University Press, 2004.

[17] G. I. Yusifova, "Syntactic Features of English Idioms," Int. J. English Linguist., vol. 3, no. 3, pp. 133-138, 2013.

[18] L. Septianasari, "Variations and Derivation of Idioms in The Kiss Novel," Premise J. English Educ. Appl. Linguist., vol. 7, no. 2, pp. 79-90, 2018
[19] R. J. Alexander, "Fixed Expressions, Idioms and Phraseology in Recent English Learner' s Dictionaries," in Euralex '92 Proceedings, 1992, no. 2, pp. 35-42.

[20] B. Lamiroy, "For a Typology of Phraseological Expressions: How to Tell an Idiom from a Collocation," in Defining Collocation for Lexicographic Purposes: From Linguistic Theory to Lexicographic Practice, no. June, A. Orlandi and L. Giacomini, Eds. Peter-Lang AG, 2016.

[21] I. Mel'cuk, "Phraseology in the Language , in the Dictionary , and in the Computer," Yearb. Phraseol., vol. 3, no. 1, pp. 31-56, 2012.

[22] R. Jukneviciene, English Phraseology and Corpora: An Introduction to Corpus-based and Corpus-driven Phraseology. Vilnius: Vilniaus Universitetas, 2017.

[23] R. A. Spears, Dictionary of American Idioms and Phrasal Verbs. New York: McGraw-Hill, 2005. 